\begin{tabular}{|l|l|}
\hline & \\
\hline
\end{tabular}

APRESENTAÇÃO

\title{
Digitalização e dataficação da vida
}

\author{
Digitization and datafication of life \\ Digitalización y datificación de la vida
}

\section{Jean Segata ${ }^{1}$ \\ orcid.org/0000-0002-2544-0745}

jeansegata@gmail.com

\section{Theophilos Rifiotis ${ }^{2}$}

orcid.org/0000-0003-1515-6633

rifiotis@gmail.com

Recebido em: 25 maio 2021 Aprovado em: 26 maio 2021 Publicado em: 24 ago. 2021

\section{(c) (1)}

Artigo está licenciado sob forma de uma licença Creative Commons Atribuicão 4.0 Internacional.
Resumo: A digitalização e a dataficação são faces de um amplo e pervasivo processo de modelagem que reduz a complexidade e a contingência da vida a códigos e dados. O conjunto de trabalhos que aqui reunimos analisam a sua emergência contemporânea e apontam para agendas de pesquisa que exaltam a sua critica na pesquisa social.

Palavras-chave: Digitalização da vida. Dataficação da vida. Cibercultura.

Abstract: Digitization and datafication are part of a broad and pervasive modeling process that reduces the complexity and contingency of life to codes and data. The set of works that we have gathered here analyze their contemporary emergence and point to research agendas that exalt their criticism in social research. Keywords: Digitization of life. Datafication of life. Cyberculture.

Resumen: La digitalización y la datificación son parte de un proceso de modelado amplio y omnipresente que reduce la complejidad y la contingencia de la vida de los códigos y los datos. El conjunto de trabajos que aqui reunimos analiza su emergencia contemporánea y apunta a agendas de investigación que exaltan su crítica en la investigación social.

Palabras clave: Digitalización de la vida. Dataficación de la vida. Cibercultura.

\section{Introdução}

A vida não é digital, mas a sua expressão tem sido. Corpos, alimentos, fenômenos climáticos, políticos e sociais e tendências econômicas ou epidemiológicas são representadas por dígitos que quantificam, classificam, ordenam, intencionam e transformam a nós e as nossas relações com outras criaturas, artefatos e ambientes. Vivemos experiências que nos mostram cada vez mais a multiplicidade de agenciamentos que articulam tecnossocialidade - como processo de construção sociocultural associado às técnicas, especialmente da computação e da informação, e a biossocialidade, como desdobramento da biopolítica que ganha uma nova ordem de produção da vida, da natureza e do corpo através de intervenções técnicas fundamentadas na biologia (Escobar 2016a).

Essa presença cada vez mais persuasiva de dispositivos sociotécnicos e a multiplicação de técnicas que vêm modificando as nossas relações com a natureza e produzindo mudanças na sua própria concepção podem e devem ser pensadas de forma global e, ao mesmo tempo, 
com seus atravessamentos locais e particulares, incluindo grupos étnicos, classe, gênero ou sentidos e práticas de saúde. São questões que apelam para a tematização do hibridismo e da distribuição da agência. Além de aparente novidade, tais questões se revelam estratégicas e motivo de embates dentro das ciências humanas e sociais, especialmente para o campo circunscrito no presente dossiê, sobre a digitalização e a dataficação da vida.

O escopo mais amplo em que essas questões se inscrevem vem sendo desenvolvido desde a década de 1980, através da reflexão crítica e permanente dos fundamentos da pesquisa, principalmente sobre a relação sujeito-objeto, natureza-cultura e sociedade-técnica. Lembremos, por exemplo, das publicações de Bruno Latour como Une sociologie sans objets? Remarques sur l'interobjectivité (Latour 1994a) ou mais conhecida delas, Jamais fomos modernos (Latour 1994b), publicado, originalmente, em 1991. É digno também de ser mencionado o trabalho de Arturo Escobar (2016a) intitulado "Welcome to cyberia: notes on the Anthropology of Cyberculture", originalmente publicado em 1994 na prestigiosa Current Anthropology seguido de importantes comentários incluidos naquele número. Porém, o trabalho mais emblemático e radical daquele momento foi publicado originalmente em 1991 por Donna Haraway e intitulado Manifesto ciborgue: ciência, tecnologia e feminismo-socialista no final do século XX (Haraway 2000). A leitura desses trabalhos continua atual e pode nos auxiliar na definição dos rumos e potencialidades das pesquisas apresentadas neste volume. Desde aqueles debates iniciados há quatro décadas até então, tem sido cada vez mais relevante e perturbador o modo como a linguagem das moléculas e das partículas se tornou saliente na vida cotidiana: DNA, calorias, niveis de dióxido de carbono ou número de likes. Cada vez mais, softwares e combinações de ácidos e proteínas inscrevem realidades sustentadas pela confiança no cálculo computacional e na materialidade universalizável da biologia (Segata 2017). Tomar esse tópico em consideração pode desenhar, assim, um projeto de grande envergadura com profundos desdobramentos que, ao nosso ver, poderia ser encarado, no seu conjunto, como uma possibilidade de revisão crítica, conceitual e metodológica para as ciências humanas e sociais na contemporaneidade.

A digitalização e a dataficação são faces deste amplo e pervasivo processo de modelagem que reduz a complexidade e a contingência da vida a códigos e dados. O conjunto de trabalhos que aqui reunimos analisa a sua emergência contemporânea e aponta para agendas de pesquisa que exaltam a sua crítica na pesquisa social. Esses trabalhos impelem uma atualização do campo de estudos que, em certo momento, se convencionou chamar de "cibercultura". Seguindo distintas orientações teóricas e metodológicas, os artigos deste dossiê apontam para uma renovada compreensão dos processos de mundialização sustentados por infraestruturas digitais de toda ordem - redes sociais da internet, programas de biossegurança, capitalismo de plataformas ou novas demandas educacionais e de ferramentas de pesquisa, incluindo possibilidades e desafios postos em relevo no tempo catastrófico que temos vivido com a pandemia de Covid-19 e suas atividades "remotas".

O presente volume traz trabalhos que mostram a limitação e mesmo a impossibilidade de uma categoria abrangente para representar o conjunto de processos em cursos. Nele, encontraremos distintas abordagens que problematizam a universalização e a exterioridade pressupostas, por exemplo, na categoria "cibercultura" e o modo como ela emprega noções como "uso", "apropriação" ou "significação", que replicam dicotomias entre digital e analógico, on-line e off-line, sujeito humano e objeto técnico e assim por diante (Rifiotis 2012). O que esse movimento de atualização nos convoca a perceber é que esse processo generalizado e onipresente de perturbação sociocultural e produção da vida e da natureza por meio de tecnologias digitais não se refere a um tópico ou a um campo de pesquisa contornável, que pode ser varrido para debaixo do tapete de outras frentes de interesse. Nas palavras de Arturo Escobar, no comentário que fez para quarta capa 
do nosso livro Politicas etnográficas no campo da cibercultura (Segata e Rifiotis 2016),

desde o corpo até as comunicações e economia; das relações pessoais às mobilizações coletivas; e desde os aparatos de vigilância (surveillance) até os serviços de saúde, educação e as noções de cidadania - em todos estes campos e em muitos mais, a cibercultura tem trazido consigo um intenso "repovoamento" das nossas vidas por atores não humanos de forma tão ubiqua que já são quase invisiveis (Escobar 2016b, s.p.).

É claro que sempre houve um certo vai-e-vem de foco que caracterizou os interesses no campo que se desenha com a digitalização e datificação da vida: ora mais centrados nos artefatos, ora nos humanos. Inicialmente, era destacada a análise psico-sociológica sobre os "impactos" dos computadores nas emoções, no lazer e no trabalho (Turkle 1989; Carvalho 2000; Lévy 2003). Com a emergência da internet, ganhou corpo o interesse pela diferenciação entre identidades e relações on-line e off-line e a globalização (Silva 2000; Castells 2000; Máximo 2006). No caso brasileiro, também ficou evidente um colapso e até mesmo uma dramática redução do amplo e potente escopo desse campo, convertido a um "novo processo" de comunicação e informação, enquanto as agendas do ativismo do software livre "corriam por fora", inscritas em outro debate, que envolveu longas disputas sobre a governança da internet no pais (Trivinho 2008; Solagna 2020).

A antropologia, de modo geral, esteve investida em muitas destas frentes, mas o Grupo de Estudos em Ciberantropologia - GrupCiber (Ufsc), em particular, se colocou de maneira crítica a esses movimentos, desde a sua constituição, há 25 anos. Primeiramente, por contestar as análises polarizadas entre prejuizos e soluções, que definiam o lugar e a qualidade da emergência das novas tecnologias digitais na vida cotidiana (Rifiotis 2010). Daí a insistência em uma perspectiva político-etnográfica, ainda que ela tenha, de início, nos cobrado um certo apego às camadas do digital mais "povoadas de gente" (Segata 2016; Rifiotis 2016). Era uma antropologia cujo antropos ainda não estava tensionado por uma abertura do social como um coletivo mais que humano. Segundo, porque foi justamente a crítica sociotécnica, robustamente influenciada pela Teoria Ator-Rede e pelos estudos multiespécie, que permitiu avançar em produções nas quais emaranhado sempre contingente de infraestruturas, materialidades e discursos que é mobilizado para atuar os dispositivos digitais e suas formas de relação ganhou lugar junto com os humanos nas etnografias, com protagonismos politicos e biografias legiveis (Segata 2017, 2020a, 2020b).

O horizonte geral deste dossiê promove, então, a ideia de que a pesquisa em ciências sociais e humanas precisa, cada vez mais, dar atenção à vida inscrita em códigos, algoritmos, artefatos, dispositivos técnicos e de informação, inclusive na definição das suas abordagens. Nesse sentido, o objetivo deste volume é contribuir para a ampliação de métodos e técnicas de pesquisa social, suas implicações conceituais e mesmo epistemológicas, em favor de análises críticas sobre os múltiplos atravessamentos do digital na contemporaneidade.

Abrindo o dossiê, o artigo intitulado "Dataficação da vida", de André Lemos apresenta, situa e problematiza a noção de digitalização e datificação, destacando a relevância da segunda para a análise social e a necessidade de tirarmos consequências analíticas dos atravessamentos da vida contemporânea pela plataformização, dataficação e da performatividade algoritmica. Ela excede e complexifica os processos de digitalização à medida que atuam sujeitos e coletividades. Nas palavras do autor, "a dataficação é a tradução de intenções, ações, reflexos, sentimentos em dados operacionalizáveis para gerar novas ações preditivas (coletivas ou individuais) partir de coleta extensiva de informações". Lemos, assim, destaca o modo como na dataficação da vida, ações, emoções, intenções, erros e comentários, transformam-se em dados que são posteriormente ampliados em ações coletivizadas que retornarão de forma personalizada, fluida e aberta a novas aprendizagens e reciclagens com a função de induzir comportamentos.

O segundo artigo, "Antropologia digital não é etnografia: explicação cibernética e transdisci- 
plinaridade", de Letícia Cesarino, ecoa a defesa antropológica da etnografia e o investimento em incorporar a técnica, a linguagem e a corporalidade no estudo dos dispositivos digitais conectados à internet. No entanto, ele traz uma renovada crítica metodológica para a pesquisa antropológica no campo das tecnologias digitais, na recuperação da noção de explicação cibernética de Gregory Bateson - "um tipo de sensibilidade, de atenção ao mundo enquanto uma composição de sistemas não-lineares co-emergentes, que é gradualmente cultivada e encorporada (embodied)". Para Cesarino, a tarefa da antropologia na pesquisa sobre a digitalização e dataficação da vida não se restringe a abrir as caixas pretas dos sistemas algoritmos e apoiar marcos regulatórios de suas corporações. Antes, ela a convoca para o engajamento aos novos sistemas de peritos ciberneticamente orientados, para pensar os "efeitos anti-estruturais - não-pretendidos porém sistêmicos, da plataformização".

Na sequência, o artigo intitulado "Correndo para não perder nada: temporalidade ansiosa e a frustração do (i)limitado", de Maria Paula Sibilia e Manuela Arruda Galindo, aborda os efeitos da digitalização da vida na forma como é vivenciada atualmente a temporalidade. A partir de uma densa revisão de literatura, as autoras mostram como "a vida digital" tem se tornado extenuante ao impelir o autocontrole em meio a uma cultura da livre escolha, forçando a táticas de proteção como o silenciamento das notificações dos dispositivos, o estabelecimento de pautas pessoais de uso e as tentativas de abandono do estado alerta contínuo. Sobremaneira, fica destacada a ansiedade que resulta do conflito entre o estímulo para consumir ilimitadamente produtos audiovisuais disponiveis em plataformas de streaming, a frustração pela persistência das limitações de tempo para fazer isso e o seu conseguinte "medo de ficar por fora".

No quarto artigo, de Lúcia Santaella e Dora Kaufman, intitulado "Os dados estão nos engolindo?" nos encontramos novamente com definições e discussões sobre big data, dataficação e dataísmo, tomados por elas como três conceitos e práticas interconectadas, mas irredutiveis: o primeiro, referindo-se, nas palavras das autoras, "ao agigantamento e desmesura de dados gerados, armazenados e disponibilizados pelos meios digitais"; o segundo, diz respeito a transformação de todos os elementos da vida em sociedade sob o formato de dados - quatificáveis, comparáveis e convertidos em valor; e o último, diz respeito "ao culto aos dados como fonte suprema de compreensão do mundo". O artigo nos traz uma importante critica sobre o que chamam de "novas acrobacias do capitalismo", por meio de uma revisão de como este universo cada vez mais complexo dos dados se converteu uma valiosa indústria na contemporaneidade, que nos engole a todo tempo.

O artigo de Alana Soares Albuquerque, intitulado "Máquinas de previsão e controle e a crise do possivel", ressalta também mais um importante tópico desse universo explorado sob a rubrica da digitalização e da dataficação: uma espécie de contínua colonização do futuro por meio da vigilância algoritmica e suas tecnologias de predição e sugestão. No ensaio, a autora também critica a confusão entre a modelagem e a vida, inscrita sob a ideia de que ela poderia ser prevista, calculada - e prescrita - de forma cada vez mais precisa a partir de um futuro estocado na "memória do computador". Um processo que ela sintetiza como sendo uma nova conversão do possivel em provável, que nos impele cada vez mais a análises criticas sobre o futuro imaginado, sobretudo aquele criado, justamente, a partir da firmação dessa imaginação forjada por dados combinados.

O sexto artigo deste dossiê, intitulado "No desligar das câmeras: experiências de estudantes de ensino superior com o ensino remoto no Covid-19", de Maria Elisa Máximo, nos oferece uma elucidativa experiência etnográfica sobre os desafios postos pela pandemia no universo educacional. Voltada a destacar a dimensão vivencial das tecnologias digitais, Máximo mostra como as práticas excedem os projetos educacionais transcendendo a instrumentalização tecnológica ao se alinhar às gramáticas interativas das sociabilidades contemporâneas. $O$ artigo coloca em relevo um conjunto de desafios para o ensino e para a pesquisa em tempos de pandemia, que envolve a prepara- 
ção de professores e pesquisadores, o acesso a computadores e a redes com conexão estável à internet, e sobremaneira, a dimensão concreta da precarização do trabalho em educação que vem sendo disfarçado sob o manto da inovação.

Na continuidade do dossiê, o trabalho de Wallace Carriço de Almeida e de Edméa Santos, intitulado "Chatbots para a formação docente: novas possibilidades de aprendizagem em rede", apresenta uma outra perspectiva sobre os processos que envolvem digitalização e dataficação da vida no contexto da educação. $O$ trabalho resulta de uma pesquisa que visa analisar os contextos e as repercussões das fakes news em favor do desenvolvimento de metodologias de pesquisa-formação na cibercultura em tempos de pós-verdade. Trata-se de um esforço para pensar na formação docente em rede, sobretudo investido na formação de professores preparados - letrados, e instrumentalizados - para atuar no processo de reconquista do lugar da verdade, sobremaneira engajados na criação e na propagação de interfaces digitais que favoreçam práticas educativas democráticas e que potencializem os sentimentos de pertença, colaboração e cidadania.

O nono artigo do dossiê, intitulado "Selfie e dataficação do cotidiano: um olhar etnográfico para as práticas e políticas material-discursivas", de Leonardo Pastor, apresenta as práticas e as politicas material-discursivas envolvidos na produção e no compartilhamento de autorretratos em redes sociais da internet. No argumento do autor, trata-se de experiências que criam novas possibilidades de conversação em ambientes que dataficam a vida cotiadiana.

É este, também, o eixo de análise que é explorado no artigo seguinte, de Sandra Stephanie Holanda Ponte Ribeiro, intitulado "Sobre repovoar narrativas: o trabalho dos influenciadores digitais a partir de uma abordagem sociotécnica". Nele, a figura do influenciador enquanto produtor de ação é tensionada ao destacar a construção de influência das próprias plataformas digitais enquanto efeito de uma vasta e heterogênea rede e não com intenção de um sujeito. Assim, a autora destaca a importância da análise sociotécnica, colocando em relevo as vantagens de uma ciência social sensivel à descrição das mediações técnicas e seus arranjos onde o humano é um entre tantos elementos e não a figura-chave da ação.

O penúltimo artigo do dossiê, intitulado "Reconhecimento dataficado em plataformas digitais: lógicas e implicações", de Bruno Campanella, explora o modo como redes sociais da internet participam do desenvolvimento de um senso de identidade, atuando na transformação das demandas por reconhecimento. $O$ autor explora como as interações nessas plataformas reforçam noções de igualdade entre as pessoas e, ao mesmo tempo, a sua vontade da afirmação singular. O ponto é que a dataficação, no argumento de Campanella, atravessa esses processos, já que colapsa essas dinâmicas de reconhecimento a partir da atuação de códigos que aglutinam preferências, tendências e moralidades criando, assim, a sensação de comunidade e universalidade e, por conseguinte, convertendo esse reconhecimento em um campo fértil para anunciantes e corporações dispostas a mercantilizar a identificação.

Por fim, o último artigo, de Massimo Di Felice, intitulado "Nem naturais, nem artificiais: as infoecologias e as qualidades simpoiéticas dos ecossistemas conectados", nos lança luzes (e desafios) para pensar a complexidade da vida dataficada. Felice nos provoca a pensar o modo como as tecnologias digitais produziram infraestruturas para a produção de ambientes multiespécie cada vez mais conectados - ou seja, ambientes que tensionam os limites ou fronteiras entre o orgânico e o inorgânico materializados em humanos, animais, ambientes e artefatos, ao convertê-los em dados combináveis, rearranjáveis e redistribuiveis. O texto de Massimo mobiliza um conjunto mais amplo de debates contemporâneos, sobretudo da antropologia, que está presente, mas que excede o tópico da dataficação da vida ao envolver o que se convencionou chamar de virada ontológica e seu anseio de superação de um olhar euroamericano como fonte única da representação dos mundos, dos seus entes e relações.

Completando o dossiê, trazemos a resenha intitulada "As engrenagens do novo populismo", 
escrita por João Henrique Salles Jung à propósito do livro Os engenheiros do caos, de Giuliano da Empoli. Trata-se de um trabalho que dialoga constantemente com o propósito deste dossiê, ao trazer para o debate o uso de big data, dos algoritmos, os das fake news para tratar da emergência do populismo, ainda que, segundo a crítica de Jung, ele não o faça dentro do campo da ciberpolítica. Nesse sentido, olhar crítico do resenhista é sensivel ao reconhecimento da importância contemporânea do trabalho de Giuliano da Empoli ao lançar reflexões sobre o modo como "ciência de dados já mostrou empiricamente sua capacidade de mapear e definir o comportamento eleitoral e garantir, assim, eleições", nos provocando a pesquisas que extraiam ainda mais as consequências da interseção entre conhecimento político e conhecimento algoritmico.

Considerando, assim, o conjunto de artigos aqui reunidos, o dossiê Digitalização e dataficação da vida: pervasividade, ubiquidade e hibridismos contemporâneos é um convite à problematização, por diferentes caminhos, da concepção de social ou sociedade como sendo a reunião de indivíduos humanos e seus modos de representação, ação, convivência e pertencimento. Trata-se de um esforço para a manutenção e a expansão de uma agenda de pesquisas em ciências humanas e sociais voltada a coletivos situacionais e contingentes, definidos - no centro dos debates aqui desenvolvidos - pela partilha de moléculas, por códigos binários e genéticos ou pela combinação de dados minerados por algum algoritmo. Em outras palavras, um esforço para tratar a produção e o governo da vida trazendo para o primeiro plano a atuação das tecnologias digitais e suas formas cada vez mais complexas de constituir a vida.

\section{Homenagem póstuma a Airton Luiz Jung blut ${ }^{3}$}

Este dossiê sobre Digitalização e dataficação da vida: pervasividade, ubiquidade e hibridismos contemporâneos publicado na Civitas: revista de
Ciências Sociais do PPGCS da Pucrs, é um desenvolvimento do projeto Políticas Etnográficas no Campo da Cibercultura (2016) que o Grupo de Pesquisa em Ciberantropologia (GrupCiber - Ppgas-Ufsc) vem desenvolvendo nos últimos 25 anos.

Entre as parcerias que esperávamos mobilizar para constituir este volume, certamente, o nome de Airton Luiz Jungblut estava entre os primeiros. Lamentamos o seu falecimento em 29 de junho de 2020 e queremos registrar aqui uma nota de reconhecimento pelas contribuições acadêmicas e pela parceria que tivemos o privilégio de compartilhar com ele ao longo dos anos. Destacamos que Airton Luiz Jungblut foi pioneiro no estudo antropológico do eixo religião-internet no Brasil, tendo contribuído para a sua consolidação nos estudos da chamada "cibercultura", tornando-se, assim, uma referência incontornável para a pesquisa neste campo.

Queremos registrar como coletivo de pesquisa que sentimos imensamente a falta do colega Airton Luiz Jungblut, cujas contribuições enriqueceriam o presente dossiê, confirmando uma vez mais seu lugar de destaque no campo, a força e a atualidade dos seus trabalhos sobre as práticas contemporâneas das diversas formas de religiosidade e seus atravessamentos sociotécnicos.

Além disso, destacamos que o presente dossiê está sendo publicado na revista Civitas, à qual ele se dedicou por anos a fio como editor, autor e organizador de vários números. Uma razão a mais que nos faz evocar a falta dele neste momento de virada nos estudos da "cibercultura", na qual acreditamos que ele também inscreveria seus trabalhos.

Nós tivemos a grata satisfação de compartithar com ele espaços acadêmicos de bancas e de eventos científicos em diferentes momentos das nossas próprias trajetórias de pesquisa. A memória nos toma de assalto neste momento e nos faz lembrar da sua perspicácia nas reflexões e o seu importante engajamento etnográfico. Nas diversas ocasiões de diálogo que mantivemos com ele ao longo de mais de uma década, ele sempre se mostrou um pesquisador atento aos 
investimentos inovadores e críticos. Cada um de nós beneficiou-se dessas qualidades que ele generosamente compartilhava, o que nos faz sentir ainda mais a falta dele em mais essa empreitada.

Que o nome de Airton Luiz Jungblut e suas contribuições para o desenvolvimento do campo de estudos da cibercultura, especialmente por revelar a importância dos atravessamentos sociotécnicos que marcam as práticas religiosas contemporâneas possa continuar a frutificar e servir de convite às novas gerações.

\section{Referências}

Carvalho, Paulo Sérgio. 2000. Interação entre humanos e computadores: uma introdução. São Paulo: Educ.

Castells, Manuel. 2000. A sociedade em rede, vol. 1. São Paulo: Paz e Terra.

Escobar, Arturo. 2016a. Comentário. In Políticas etnográficas no campo da cibercultura, organizado por Jean Segata e Theophilos Rifiotis, s. p. Brasilia: ABA Publicações.

Escobar, Arturo. 2016b. Bem-vindos à Cyberia: notas para uma antropologia da cibercultura. In Politicas etnográficas no campo da cibercultura, organizado por Jean Segata e Theophilos Rifiotis, 21-66. Brasília: ABA Publicações.

Haraway, Donna. 2000. Manifesto Ciborgue: ciência, tecnologia e feminismo-socialista no final do século XX. In Antropologia do ciborgue: as vertigens do pós-humano, organizado por Tomaz Tadeu, 33-118. Belo Horizonte: Autêntica.

Hine, Christine. 2020. A internet 3E: uma internet incorporada, corporificada e cotidiana. Cadernos de Campo 29 (2): e181370. https://doi.org/10.11606/issn.2316-9133. v29i2pe181370.

Latour, Bruno. 1994a. Une sociologie sans objets? Remarques sur l'interobjectivité. Sociologie du travail 34 (4): 587-607. https://doi.org/10.3406/sotra.1994.2196.

Latour, Bruno. 1994b. Jamais fomos modernos: ensaios de antropologia simétrica. São Paulo: Editora 34

Lévy, Pierre. 2003. A inteligência coletiva: por uma antropologia do ciberespaço, 4. ed. São Paulo: Loyola.

Rifiotis, Theophilos. 2010. Antropologia do ciberespaço: questões teórico-metodológicas sobre pesquisa de campo e modelos de sociabilidade. In Antropologia do ciberespaço, organizado por Theophilos Rifiotis et al., 15-28. Florianópolis: Editora UFSC.

Rifiotis, Theophilos. 2016. Etnografia no ciberespaço como "repovoamento" e explicação. In Politicas etnográficas no campo da cibercultura, organizado por Jean Segata e Theophilos Rifiotis, 129-152. Brasilia: ABA Publicações.
Segata, Jean. 2016. Dos cibernautas às redes. In Politicas etnográficas no campo da cibercultura, organizado por Jean Segata e Theophilos Rifiotis, 91-114. Brasília: ABA Publicações.

Segata, Jean. 2017. O Aedes aegypti e o digital. Horizontes Antropológicos 23 (48): 19-48. https://doi.org/10.1590/ s0104-71832017000200002.

Segata, Jean. 2020a. Covid-19, biossegurança e antropologia. Horizontes Antropológicos 26 (57): 275-313. https://doi.org/10.15.90/s0104-71832020000200010.

Segata, Jean. 2020b. A pandemia e o digital. Revista Todavia 7: 7-15

Solagna, Fabrício. 2020. 30 anos de governança da Internet no Brasil: coalizões e ideias em disputa pela rede, Tese em sociologia, Universidade Federal do Rio Grande do Sul (Ufrgs), Porto Alegre, RS, Brasil.

Trivinho, Eugenio. 2008. Epistemologia em ruinas: a implosão da teoria da comunicação na experiência do cyberspace. Revista Famecos 3 (5): 73-81. https://doi. org/10.15448/1980-3729.1996.5.2950.

\section{Theophilos Rifiotis}

Doutor em Sociologia pela Universidade de São Paulo (USP), São Paulo, SP, Brasil; professor titular do Departamento de Antropologia da Universidade Federal de Santa Catarina (Ufsc), Florianópolis, SC, Brasil.

\section{Jean Segata}

Doutor em Antropologia Social pela Universidade Federal de Santa Catarina (Ufsc), Florianópolis, SC, Brasil; professor adjunto do Departamento de Antropologia na Universidade Federal do Rio Grande do Sul (UFRGS), Porto Alegre, RS, Brasil.

Os textos deste artigo foram revisados pela Poá Comunicação e submetidos para validação do(s) autor(es) antes da publicação. 